\title{
Global longitudinal strain (GLS)
}

\author{
Johan H. C. Reiber ${ }^{1}$
}

Published online: 14 February 2022

(c) The Author(s), under exclusive licence to Springer Nature B.V. 2022

Dear reader,

For this February 2022 issue, I would like to discuss the use and variability in Global longitudinal strain (GLS), which has been a very popular measurement in echocardiography, but also now extending towards other imaging modalities, such as magnetic resonance imaging, and also in CT functional assessment. Although the basic principle is quite simple, being the ratio of the left ventricular perimeter at end-systole divided by that perimeter at end-diastole, of course in a particular cross section of the heart, the use in daily practice apparently is still not that simple and standardized. The World Alliance Societies of Echocardiography has proposed normal values for GLS, being $17-24 \%$ for males and $18-26 \%$ for females.

The team of Dr Oscar Mauricio Perez-Fernandez and Dr Frida Tatiana Manrique from the Cardiology Institute in Bogota, Columbia published a paper about the reliability and validity of the GLS in heart transplant patients in a tertiary hospital in Colombia [1]. They used the GLS software from two different vendors and found significant inter-vendor variability in the GLS. An illustrative example is given from their manuscript here in Fig. 1, given below with their legend.

They also found significant differences in ROC analyses in the estimation of normal LVEF: area-under-the-curve (AuC) for Philips 0.63 and for GE 0.82.

So, what are the lessons that we can learn from the fact that such differences between vendors are likely to remain: (1) in specific patient populations or clinical research use one single vendor solution; (2) have such analyses be carried out in a 3D lab or central analysis room with a vendorindependent software solution. It is also clear that such set ups may not always be very practical or even possible in daily practice and that the vendors should try to adapt their solutions towards a broadly acceptable standard, certainly for such a very simple parameter as the GLS!

I wish you much pleasure in reading these and the other papers in this issue of the International Journal of Cardiovascular Imaging.
Johan H. C. Reiber

J.H.C.Reiber@lumc.nl

1 Leiden University Medical Center, Leiden, The Netherlands 


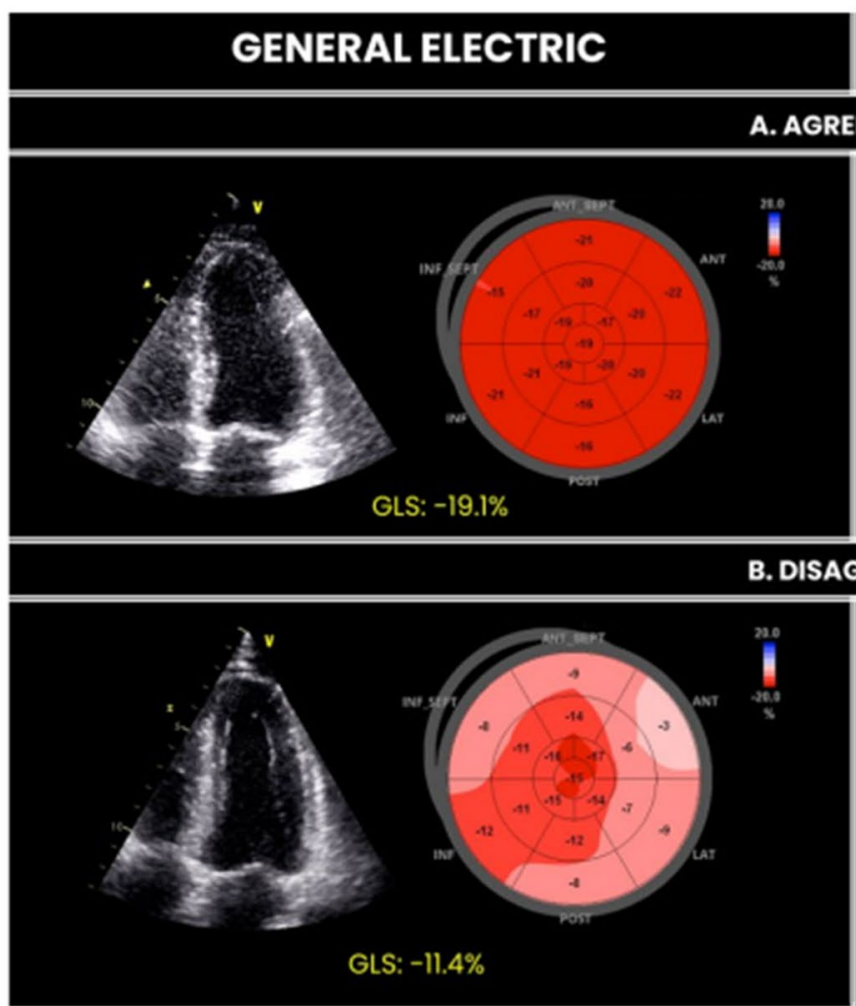

Fig. 1 Simultaneous inter-vendor GLS analysis performed in two different HT patients. Panel A shows apical four-chamber frame and strain analysis with a small inter-vendor GLS absolute difference of

\section{Reference}

1. Perez-Fernandez OM, Medina HM, Lopez M et al (2021) Global longitudinal strain in heart transplantation recipients using different vendors: reliability and validity in a tertiary hospital in Colombia. Int J Cardiovasc Imaging. https://doi.org/10.1007/ s10554-021-02398-7

\section{PHILLIPS}

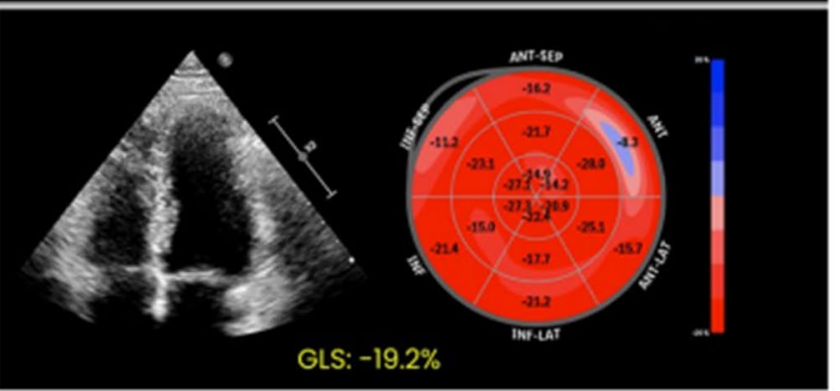

GLS: $-19.2 \%$

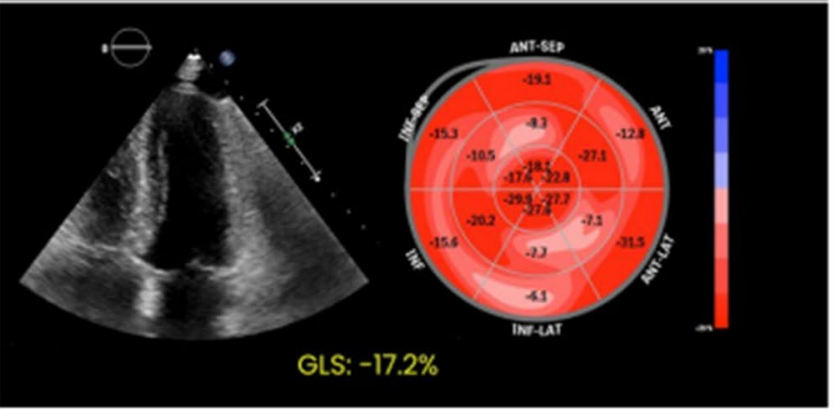

$0.1 \%$. Conversely, panel B shows a wide inter-vendor GLS disagreement (absolute difference of 5.8\%)

Publisher's Note Springer Nature remains neutral with regard to jurisdictional claims in published maps and institutional affiliations. 